\title{
Risk of Non-Hodgkin Lymphoma in Relation to Tricyclic Antidepressant Use
}

\author{
Sarah J. Lowry, PhD, Jessica Chubak, PhD, Oliver W. Press, MD, Barbara McKnight, PhD, \\ and Noel S. Weiss, MD, DrPH \\ Group Health Research Institute, Group Health Cooperative
}

\begin{abstract}
Purpose-We investigated the relationship between use of tricyclic antidepressants (TCA) and risk of non-Hodgkin lymphoma (NHL). Previous studies provided some evidence of an association, but did not assess risk of NHL subtypes.

Methods-Cases and controls were members of Group Health (GH), an integrated healthcare delivery system. Cases were persons diagnosed with NHL between 1980-2011 at age $\geq 25 ; 8$ controls were matched to each case on age, sex, and length of enrollment. Information on prior TCA use was ascertained from automated pharmacy data. Conditional logistic regression was used to calculate ORs and $95 \%$ CIs for NHL, overall and for common subtypes, for various patterns of TCA use.

Results-We identified 2,768 cases and 22,127 matched controls. We did not observe an appreciably increased risk of NHL among TCA ever-users compared to non-users ( $\mathrm{OR}=1.1$; $95 \% \mathrm{CI}=1.0-1.2)$. Overall risk of NHL was associated to at most a small degree with longer-term use $(\mathrm{OR}=1.2 ; 95 \% \mathrm{CI}=1.0-1.4 ; \geq 10$ prescriptions $)$, high-dose use $(\mathrm{OR}=1.1 ; 95 \% \mathrm{CI}=0.8-1.5$; $250 \mathrm{mg})$, or non-recent use $(\mathrm{OR}=1.0 ; 95 \% \mathrm{CI}=0.9=1.2 ;>5 \mathrm{y}$ ago $)$. TCA use was not associated with NHL subtypes, except chronic lymphocytic leukemia/small lymphocytic lymphoma $(\mathrm{OR}=1.5$; $95 \% \mathrm{CI}=1.1-2.0$; longer-term use).
\end{abstract}

Conclusions-We found little evidence that TCA use increases risk of NHL, overall or for specific common subtypes of NHL.

\section{MeSH Terms}

Lymphoma, non-Hodgkin; Antidepressive Agents, Tricyclic; Epidemiology; Case-Control Studies

\section{Introduction}

Non-Hodgkin lymphomas (NHLs) are a heterogeneous group of more than 40 cancers of the lymphoid cells, distinct in terms of morphology, immunophenotype, genetic features, and prognosis, ${ }^{1,2}$ as well as etiology. ${ }^{3-8}$ The strongest known risk factor for NHLs as a whole is severe immune impairment, but other etiologies are not well understood. ${ }^{1,9}$ Previous studies have provided some evidence of an association between prior use of tricyclic antidepressants (TCAs) and NHL risk. A population-based cohort study in Denmark observed a 50\% higher

\footnotetext{
(C) 2013 Elsevier Inc. All rights reserved.

Correspondence to: Sarah J. Lowry.

Publisher's Disclaimer: This is a PDF file of an unedited manuscript that has been accepted for publication. As a service to our customers we are providing this early version of the manuscript. The manuscript will undergo copyediting, typesetting, and review of the resulting proof before it is published in its final citable form. Please note that during the production process errors may be discovered which could affect the content, and all legal disclaimers that apply to the journal pertain.
} 
risk of NHL in TCA users compared to non-users (95\% confidence interval (CI) 1.1-2.2), and a more than doubled risk associated with longer-term use ( $>10$ prescriptions) among persons with $\geq 5$ years of follow-up (relative risk (RR) $2.5 ; 95 \% \mathrm{CI}=1.4-4.3$ ). ${ }^{10}$ A second study in Canada used population-based cancer registries and ascertained use of TCAs by self-report; this study observed a more modest association with long-term ( $\geq 25$ months) versus no use (odds ratio (OR) 1.6, 95\% CI=0.8-3.3), and little evidence for an association with ever-use (OR 0.8, 95\%CI=0.5-1.3). ${ }^{11}$ Neither study investigated whether the association between TCA use and NHL varied by NHL type, or by TCA type.

TCAs, which have been in use since the 1950s, affect a wide range of neurotransmitter systems, including alpha-1, histaminic and muscarinic receptors. ${ }^{12}$ They are potent H1 antihistamines, which may also influence lymphoma risk. ${ }^{4}$ TCAs are associated with a range of relatively strong side effects, which have likely contributed to the decline in their psychiatric use in favor of newer antidepressants. ${ }^{13}$ However, providers are increasingly prescribing TCAs for chronic pain and sleep disorders, though generally in lower doses than those prescribed for depression. ${ }^{14-16}$

We undertook this study to evaluate whether use of tricyclic antidepressants, overall and grouped by duration, dose, recency, and type, is associated with an increased risk of NHL. We also investigated whether the association, if any, differs across the following more common types of NHL: diffuse large B-cell lymphoma (DLBCL), chronic lymphocytic leukemia/small lymphocytic lymphoma (CLL/SLL), follicular lymphoma (FL), and the plasma cell neoplasms (PCN), multiple myeloma (MM) and plasma cell leukemia (PCL). (Figure 1)

\section{Methods}

This study was conducted among enrollees at Group Health Cooperative (GH), a consumergoverned, non-profit health system in Washington state and Northern Idaho. GH currently provides health coverage to $>650,000$ enrollees; there were approximately 300,000 enrollees at the start of the study period. ${ }^{17}$ To select cases, we first identified all persons who had been diagnosed with NHL between 1/1/1980 and 3/31/2011 at 225 years of age, who were enrolled for $\geq 2$ years before diagnosis, and who resided in one of the 13 counties included in the western Washington Surveillance Epidemiology and End Results (SEER) registry at the time of diagnosis. The date of the case's diagnosis served as the reference date. We matched eight controls to each case on age ( \pm 24 months), sex, and length of enrollment at GH prior to the reference date, and after the start of the pharmacy database in 1977.

Cancer diagnoses were ascertained using GH automated records with linkage to the SEER registry. ${ }^{18}$ We identified NHL cases using all ICD-O-3 histology codes for NHL in the SEER registry, according to the most recent World Health Organization (WHO) NHL classification system. ${ }^{19}$ Common subtypes of NHL (Figure 1) were identified using ICDO-3 codes. ${ }^{19}$ Although ICD-O-3 codes did not exist before 2001, all earlier ICD-O codes in the registry have since been converted to ICD-O-3 codes by the SEER program. ${ }^{20,21}$ Plasma cell neoplasms, including multiple myeloma, are included as a type of NHL by the WHO ICD-O-3 classification system. ${ }^{22}$

We excluded cases and controls who had been diagnosed with any cancer before the reference date except non-melanoma skin cancer. We also excluded persons who, prior to the reference date, likely had a condition consistently associated with increased risk of NHL, including HIV/AIDS, Sjogren syndrome, systemic lupus erythematosus, celiac disease, dermatitis hepatiformis, and chronic thyroiditis, ${ }^{23,24}$ as well as those who filled a prescription for a medication associated with immune impairment (methotrexate, 
azathioprine, cyclosporine, cyclophosphamide, chlorambucil, penicillamine, aurothiomalate, auranofin, 6-mercaptopurine, infliximab, adalimumab, and etanercept). 3,4,10,24-27 We used automated diagnosis codes and pharmacy data recorded before the reference date to identify these conditions and medications.

We identified prior use of TCAs using the GH pharmacy database, which includes a record for each prescription medication dispensed to GH enrollees since 1977 . Nearly all (approximately 95\%) GH members who fill prescriptions for antidepressants do so at GH pharmacies. ${ }^{28}$ Each record includes a patient identifier, medication name, strength, date dispensed, quantity dispensed, instructions for use, and drug form. We defined ever-use of TCAs as having filled $\geq 2$ prescriptions (of any TCA) before the reference date, to give some assurance that the medication was actually taken; longer-term use was defined as $\geq 10$ prescriptions (Table 1). For approximately half of TCA prescription records in our study, the intended duration of TCA use could not be determined, so we instead used the number of prescriptions dispensed as a surrogate for duration of use, for all subjects. To estimate average daily dose, pill strength (known for $97 \%$ of prescriptions) was multiplied by the number of pills prescribed per day, for the approximately half of prescriptions which included instructions for use. For prescriptions which lacked instructions for use, 1 pill per day was assumed. (Of prescriptions with instructions for use, approximately half specified 1 pill per day and half specified $>1$ pill/day; $<1 \%$ specified $<1$ pill/day.)

To compare doses across different types of TCAs, we created a standardized categorization for high versus low average daily dose. Dosages are not necessarily equivalent across different types of TCAs in terms of their therapeutic effect; for example the maximum recommended daily dose of doxepin $(300 \mathrm{mg})$ is twice that of nortriptyline $(150 \mathrm{mg}) .{ }^{29} \mathrm{In}$ the absence of any conventional equivalency conversions for dosages across TCA types, we defined $\geq 50 \mathrm{mg} /$ day as a "high" dose for all but two TCAs; 25 and $7.5 \mathrm{mg} /$ day of nortriptyline and protriptyline, respectively, were defined as high dose. ${ }^{14} \mathrm{We}$ calculated cumulative dose as the average (standardized) daily dose times the total number of prescriptions filled, and defined low cumulative dose as $\unlhd, 000 \mathrm{mg}$-prescriptions and high cumulative dose as $>1,000 \mathrm{mg}$-prescriptions (Table 1).

We collected prescription data on opioids which have been shown to have immunosuppressive properties, including codeine, methadone, morphine and fentanyl, ${ }^{30}$ as a potential confounder, because they are likely associated with both TCA use and risk of NHL. We collected data on prior use of selective serotonin reuptake inhibitors (SSRIs) in a manner similar to that for TCAs. In order to gauge the potential for confounding by depression, we compared the association between TCA use and NHL to that between SSRI use and NHL. Because previous studies of the relationship between SSRIs and NHL have not observed any such evidence, ${ }^{10}$ an association between NHL risk and TCA use, but not SSRI use, would suggest that depression did not confound the results.

We used conditional logistic regression to calculate ORs and 95\%CIs, implicitly adjusting for age, calendar time (the reference date), sex, and length of "exposure ascertainment period" through the matching process. We explicitly adjusted for a history of immunosuppressive opioid use. We repeated analyses separately for long-term and highdose use of TCAs, recency of last use, and for the more common types of TCAs (Table 1). Our primary analysis included people for whom we had pharmacy information for as few as 2 years, as the association between use of TCAs and NHL risk could potentially have a short induction-latency period. However, we restricted some analyses to subjects for whom we had $\geq 5$ years and $\geq 10$ years of pharmacy data, which included $>75 \%$ and $50 \%$ of study subjects, respectively. We adjusted for race in some analyses; race data were available on 
$99 \%$ of cases (from the SEER registry) and $65 \%$ of controls, and $>99 \%$ of matched sets included at least one control with known race.

We conducted similar analyses for the more common types of NHL: cases were limited to those with the subtype of NHL in question, and controls were limited to subjects matched to those cases. We used conditional logistic regression to estimate ORs and 95\% CIs of the risk of each NHL subtype in association with TCA ever-use; additional analyses specifically investigated ORs associated with long-term use and use of high-dose TCAs, as well as recency of use and TCA type.

\section{Results}

Our study population included 2,768 cases and 22,127 matched controls, which had similar distributions of the matching factors (Table 2). Fifteen percent of cases had filled $\geq 2$ TCA prescriptions and $7 \%$ had filled $\geq 10$ prescriptions prior to the reference date, compared to $13 \%$ and $5 \%$ of controls, respectively. (Table 3a) We observed little evidence of an increased risk of NHL among persons who had filled $\geq 2$ TCA prescriptions compared to non-users (OR: 1.1; 95\% CI: 1.0-1.3). Risk of NHL as a whole was, at most, weakly associated with longer-term use (OR: $1.2 ; 95 \% \mathrm{CI}: 1.0-1.5$ for $\geq 10$ prescriptions), high-dose use (OR: 1.2 ; $95 \%$ CI: $0.7-1.8$ for $\geq 50 \mathrm{mg}$ or equivalent), or use that ended more than 5 years prior to the reference date (OR: $0.9 ; 95 \%$ CI: $0.6-1.5$; Table $3 \mathrm{a}$ ). The various types of TCAs did not appear to be associated with an elevated risk of NHL with the possible exception of amitriptyline $(\mathrm{RR}=1.2 ; 95 \% \mathrm{CI}=1.0-1.4)$. TCA use was not associated with the individual types of NHL, with the possible exception of CLL/SLL, which was associated with longer-term TCA use (OR: 1.5; 95\% CI: 1.1-2.0; Table 3b).

In analyses adjusted for race, results were unchanged (not shown). In analyses of the association between NHL and very recent TCA use, defined as any use within 2 years of the reference date, we observed some evidence of an association with NHL risk (OR=1.3, 95\% CI=1.1-1.6; Table 3a). Low-dose rather than high-dose use appeared to account for the observed association with very recent use (low-dose users: $\mathrm{OR}=1.595 \% \mathrm{CI}=1.1-2.1$; highdose users: $\mathrm{OR}=1.3,95 \% \mathrm{CI}=0.7-2.4$; not shown).

In analyses limited to subjects with at least 5 years of pharmacy data (i.e. those enrolled for at least 5 years after the pharmacy database began and before the reference date), ORs ranged from 1.0 to 1.3 , with $95 \%$ CIs which included the null (1.0), for all patterns of TCA use (e.g. ever-use, high-dose use, TCA type) with the exception of very recent use ( $\mathrm{OR}=1.3$, $95 \% \mathrm{CI}=1.1-1.7)$. For analyses limited to subjects with at least 10 years of pharmacy data, all associations with NHL were weak or absent, with the possible exception of an increased risk among users of nortriptyline ( $\mathrm{OR}=1.4 ; 95 \% \mathrm{CI}=1.0-1.9$; Table 4$)$ ).

After adjustment for race and immunosuppressive opioid use, we observed a modest increased risk of NHL among users of SSRIs, one very similar in magnitude to that seen among users of TCAs (Table 5).

\section{Discussion}

We did not observe an appreciably increased risk of NHL among persons who had used TCAs, even among those with a high average daily dose, high cumulative dose, or long duration of use. We observed little evidence for an elevated risk of the separate major types of NHL among persons with a history of TCA use, with the possible exception of chronic lymphocytic leukemia/small lymphocytic lymphoma (CLL/SLL), for which longer-term TCA use was associated with a 50\% higher risk. 
We are aware of two previous studies which investigated this question. A study conducted in Denmark ${ }^{10}$ reported a $50 \%$ higher risk of NHL risk associated with prior TCA use; this risk more than doubled with longer-term use. Similar to our study, this study used automated records to ascertain TCA use, NHL diagnoses, and potential confounders for all subjects in a defined population. Unlike our study, this study adjusted for a history of immune conditions and medications, whereas we chose to exclude subjects ( $\mathrm{n}=148$ cases, or 5\%) with immune conditions and medications in order to improve our ability to detect an association. Our reasoning was that, if TCA use did in fact increase the risk of NHLs on a relative scale, the degree to which it did so might be greatest in persons who did not have other strong risk factors. This difference could potentially account for differences in findings, if only persons with underlying immune dysfunction are susceptible to the potential effects of TCA use on lymphoma risk. However, it seems unlikely that the small portion of subjects we excluded with a history of immune disorder would so fully account for whatever underlying immune dysfunction enhances the effect of TCA use on NHL risk as to explain the large difference in risk estimates between that study and ours. A part of the difference could have been due to the fact that the Danish study adjusted for age using 10-year age categories, which could have led to residual confounding by age, as older age is positively associated with both NHL risk and history of TCA use. Finally, the RRs from that study, both for ever-use and for longer-term use, were based on relatively small numbers of exposed cases (18 and 13, respectively).

Another study of the association between TCA use and NHL risk was conducted in Canada, ${ }^{11}$ and used population-based cancer registries and self-reported use of TCAs. This study observed a more modest association than the Danish study for long-term use, defined as $\geq 25$ months, versus no use ( $\mathrm{OR}=1.6,95 \% \mathrm{CI}=0.8-3.3)$, and no evidence for an association with ever-use, defined as $\geq 2$ weeks $(\mathrm{OR}=0.8,95 \% \mathrm{CI}=0.5-1.3)$. This study recruited participants and collected exposure data via mailed questionnaires; it has been shown that self-reported antidepressant use in particular tends to be underreported. ${ }^{31}$ Non-differential underreporting by cases and controls would be expected to attenuate an association. It is plausible, however, that cases would be more likely to recall and/or report prior use of medications due to their diagnosis; this would be expected to inflate the strength of the association, which could explain an observed elevation in risk. This study did not have data on dose, or detailed data on TCA type. Because the three studies were conducted in different countries, the types of TCAs in use differed to some extent.

TCAs have been shown to be potent $\mathrm{H} 1$ antihistamines; amitriptyline and doxepin are among the most potent $\mathrm{H} 1$ antihistamines known. ${ }^{32,33}$ We are aware of only one epidemiologic study of the relationship between use of $\mathrm{H} 1$ antihistamines and the occurrence of NHL. ${ }^{4}$ In this large prospective cohort study, current, longer-term use of $\mathrm{H} 1$ antihistamines ( $\ 6$ years) was associated with an increased risk of NHL overall ( $R R=1.9$, 95\% CI $=1.2-3.0$ ). Of the 3 NHL subtypes investigated, an elevated risk of DLBCL, but not FL or CLL/SLL, was observed with current use with a duration of $\geq 6$ years (DLBCL: $\mathrm{RR}=2.3,95 \% \mathrm{CI}=1.2-4.6$; FL: $\mathrm{RR}=0.9,95 \% \mathrm{CI}=0.5-1.7$; $\mathrm{CLL} / \mathrm{SLL}: \mathrm{RR}=0.6,95 \% \mathrm{CI}=0.3-$ 1.1). ${ }^{4}$ In comparison, the present study observed a suggestion of an elevated risk of CLL/ SLL but not DLBCL or other subtypes, associated with use of a specific class of potent $\mathrm{H} 1$ antihistamines (TCAs). The mechanisms of action of $\mathrm{H} 1$ antihistamines are not well understood. However, H1 receptor stimulation has been shown to alter immune function in various ways, including inducing pro-inflammatory effects, and playing a role in antigenreceptor mediated signaling pathways that trigger proliferative responses and B-cell antibody production (as reviewed by Togias ${ }^{34}$ ). Another possible mechanism may involve the intracellular histamine receptor, HIC. H1 antihistamines bind to HIC, stimulating it to upregulate lymphocyte mitogenesis. ${ }^{35} \mathrm{HIC}$ is also thought to promote the growth of transformed lymphocytes by inhibiting normal lymphocyte proliferation, which decreases 
suppressor T-lymphocyte function. ${ }^{36,37}$ Based on these findings, it seems that if antihistamines do influence lymphoma risk, the mechanism(s) by which they do so could include effects on either the early stages of lymphomagenesis, on later stages as a promoter, or both.

One strength of the present study is the use of pre-existing administrative data on TCA use, including detailed information on type, timing, and dose, which were recorded on cases and controls prior to the reference date. These data were available for both cases and controls, which reduces the potential for information bias, and eliminates concern for recall bias. The selection of cases and controls from the defined population of GH members avoids the problem of incomplete participation, as all data were collected directly from existing administrative records on both cases and controls, and every subject identified as a potential case or control thus was included in the study.

One possible limitation is our inability to ascertain use of TCAs that occurred prior to a subject's enrollment at GH or before the start of the pharmacy database in 1977. However, the GH population is relatively stable, and $50 \%$ of subjects had $>10$ years of pharmacy data available (i.e. they were enrolled for $>10$ years after 1977 and before the reference date). Another potential limitation is that ICD-O codes have undergone multiple revisions since 1980, and the latest classification system may still not capture the most etiologically relevant NHL subgroups. However, most changes in coding have involved rarer subtypes, while common types have remained relatively stable. In one study, 84-89\% of ICD-O codes assigned between 1988-1994 were found to be correctly converted to ICD-O-3 codes for the most common NHL subtypes. ${ }^{38}$ Further, previous studies have shown important differences in the pattern of incidence among NHL subgroups using ICD-O-3 codes, ${ }^{4}$ so this system likely captures an important portion of etiologic variability across separate types of NHL. It is possible that some patients were included in more than one "TCA type" category, if they had filled 2 or more prescriptions for multiple TCA types (e.g. amitriptyline and doxepin). However, given the largely null findings for TCA types and overall, it seems unlikely that excluding such patients would alter the results. Finally, there is the possibility for confounding by indication; TCAs are prescribed for pain and sleep disorders, which we were unable to ascertain, and for depression, which we also were not able to ascertain with any sensitivity from the records available to the study. The presence of a weak association between SSRI use and NHL risk similar in size to that between use of TCAs and NHL argues that a small amount of confounding by depression could have been present.

The results of this study do not support the hypothesis that use of TCAs influences the risk of NHL as a whole. Subsequent studies of this question, ones that are able to separate cases according to individual types of NHL, will be useful in determining whether our observation of a $50 \%$ increase in risk of CLL/SLL is the result of anything other than chance.

\section{References}

1. Swerdlow, SHCE.; Harris, NL.; Jaffe, ES.; Pileri, SA.; Stein, H.; Thiele, J., et al., editors. WHO Classification of Tumours of Haematopoietic and Lymphoid Tissues. 4. Lyon, France: International Agency for Research on Cancer, World Health Organization; 2008.

2. Han X, Kilfoy B, Zheng T, Holford TR, Zhu C, Zhu Y, et al. Lymphoma survival patterns by WHO subtype in the United States, 1973-2003. Cancer Causes Control. 2008; 19(8):841-58. [PubMed: 18365759]

3. Smedby KE, Hjalgrim H, Askling J, Chang ET, Gregersen H, Porwit-MacDonald A, et al. Autoimmune and chronic inflammatory disorders and risk of non-Hodgkin lymphoma by subtype. $\mathrm{J}$ Natl Cancer Inst. 2006; 98(1):51-60. [PubMed: 16391371] 
4. Erber E, Lim U, Maskarinec G, Kolonel LN. Common immune-related risk factors and incident non-Hodgkin lymphoma: the multiethnic cohort. Int J Cancer. 2009; 125(6):1440-5. [PubMed: 19444913]

5. Smedby KE, Askling J, Mariette X, Baecklund E. Autoimmune and inflammatory disorders and risk of malignant lymphomas--an update. J Intern Med. 2008; 264(6):514-27. [PubMed: 19017176]

6. Cerhan JR, Wallace RB, Dick F, Kemp J, Parker AS, Zheng W, et al. Blood transfusions and risk of non-Hodgkin's lymphoma subtypes and chronic lymphocytic leukemia. Cancer Epidemiol Biomarkers Prev. 2001; 10(4):361-8. [PubMed: 11319177]

7. Carreon JD, Morton LM, Devesa SS, Clarke CA, Gomez SL, Glaser SL, et al. Incidence of lymphoid neoplasms by subtype among six Asian ethnic groups in the United States, 1996-2004. Cancer Causes Control. 2008; 19(10):1171-81. [PubMed: 18543071]

8. Anderson JR, Armitage JO, Weisenburger DD. Epidemiology of the non-Hodgkin's lymphomas: distributions of the major subtypes differ by geographic locations. Non-Hodgkin's Lymphoma Classification Project. Ann Oncol. 1998; 9(7):717-20. [PubMed: 9739436]

9. Kinlen L. Immunosuppressive therapy and acquired immunological disorders. Cancer Res. 1992; 52(19 Suppl):5474s-5476s. [PubMed: 1394156]

10. Dalton SO, Poulsen AH, Norgaard M, McLaughlin JK, Johansen C, Friis S. Tricyclic antidepressants and non-Hodgkin lymphoma. Epidemiology. 2008; 19(4):546-9. [PubMed: 18552589]

11. Bahl S, Cotterchio M, Kreiger N, Klar N. Antidepressant medication use and non-Hodgkin's lymphoma risk: no association. Am J Epidemiol. 2004; 160(6):566-75. [PubMed: 15353417]

12. Hirsch, M.; Birnbaum, RJ. Antidepressant medication in adults: Tricyclics and tetracyclics. In: Schwenk, TL., editor. UpToDate Online 17.3. 2009.

13. Anderson IM. Selective serotonin reuptake inhibitors versus tricyclic antidepressants: a metaanalysis of efficacy and tolerability. J Affect Disord. 2000; 58(1):19-36. [PubMed: 10760555]

14. Pharmacology of antidepressants. UpToDate; 2010. UpToDate Online 17.3.

15. McQuay HJ, Tramer M, Nye BA, Carroll D, Wiffen PJ, Moore RA. A systematic review of antidepressants in neuropathic pain. Pain. 1996; 68(2-3):217-27. [PubMed: 9121808]

16. Breivik H, Collett B, Ventafridda V, Cohen R, Gallacher D. Survey of chronic pain in Europe: prevalence, impact on daily life, and treatment. Eur J Pain. 2006; 10(4):287-333. [PubMed: 16095934]

17. Health, G., editor. Group Health (for visitors). Vol. 2012. Seattle: Group Health Cooperative; 2012. History of the Cooperative.

18. Surveillance, Epidemiology, and End Results (SEER) Program, SEER*Stat Database. National Cancer Institute, DCCPS, Surveillance Research Program, Cancer Statistics Branch; 2011.

19. Morton LM, Turner JJ, Cerhan JR, Linet MS, Treseler PA, Clarke CA, et al. Proposed classification of lymphoid neoplasms for epidemiologic research from the Pathology Working Group of the International Lymphoma Epidemiology Consortium (InterLymph). Blood. 2007; 110(2):695-708. [PubMed: 17389762]

20. Percy, C.; Fritz, A.; Ries, LA., editors. Cancer Statistics Branch Division of Cancer Control and Population Sciences Surveillance Epidemiology and end Results Program. Conversion of neoplasms by topology and morphology from the ICD-2 to ICD-3. Bethesda: National Cancer Institute; 2001. p. 166

21. Van Holten, V.; Percy, C., editors. Surveillance Program Division of Cancer Prevention and Control. Addendum to conversion of neoplasms by topography and morphology from the International Classification of Diseases for oncology (ICD-0). Bethesda: National Cancer Institute; 1992.

22. Swerdlow, SH.; Campo, E.; Harris, NL.; Jaffe, ES.; Pileri, SA.; Stein, H., et al., editors. WHO Classification of Tumours of Haematopoietic and Lymphoid Tissues. 4. Lyon, France: International Agency for Research on Cancer, World Health Organization; 2008.

23. Anderson LA, Gadalla S, Morton LM, Landgren O, Pfeiffer R, Warren JL, et al. Population-based study of autoimmune conditions and the risk of specific lymphoid malignancies. Int J Cancer. 2009; 125(2):398-405. [PubMed: 19365835] 
24. Smedby KE, Baecklund E, Askling J. Malignant lymphomas in autoimmunity and inflammation: a review of risks, risk factors, and lymphoma characteristics. Cancer Epidemiol Biomarkers Prev. 2006; 15(11):2069-77. [PubMed: 17119030]

25. Grulich AE, Vajdic CM, Cozen W. Altered immunity as a risk factor for non-Hodgkin lymphoma. Cancer Epidemiol Biomarkers Prev. 2007; 16(3):405-8. [PubMed: 17337643]

26. Anderson JR, Cain KC, Gelber RD. Analysis of survival by tumor response and other comparisons of time-to-event by outcome variables. J Clin Oncol. 2008; 26(24):3913-5. [PubMed: 18711176]

27. Cuttner J, Spiera H, Troy K, Wallenstein S. Autoimmune disease is a risk factor for the development of non-Hodgkin's lymphoma. J Rheumatol. 2005; 32(10):1884-7. [PubMed: $16206341]$

28. Fulton-Kehoe D, Rossing MA, Rutter C, Mandelson MT, Weiss NS. Use of antidepressant medications in relation to the incidence of breast cancer. Br J Cancer. 2006; 94(7):1071-8. [PubMed: 16523201]

29. Mancano, MAaJG. Frequently Prescribed Medications: Drugs You Need to Know. Sudbury, MA: Jones and Bartlett Learning, LLC; 2012.

30. Dublin S, Walker RL, Jackson ML, Nelson JC, Weiss NS, Von Korff M, et al. Use of opioids or benzodiazepines and risk of pneumonia in older adults: a population-based case-control study. $\mathrm{J}$ Am Geriatr Soc. 2011; 59(10):1899-907. [PubMed: 22091503]

31. Boudreau DM, Daling JR, Malone KE, Gardner JS, Blough DK, Heckbert SR. A validation study of patient interview data and pharmacy records for antihypertensive, statin, and antidepressant medication use among older women. Am J Epidemiol. 2004; 159(3):308-17. [PubMed: 14742292]

32. Cusack B, Nelson A, Richelson E. Binding of antidepressants to human brain receptors: focus on newer generation compounds. Psychopharmacology (Berl). 1994; 114(4):559-65. [PubMed: 7855217]

33. Richelson E. Tricyclic antidepressants and histamine H1 receptors. Mayo Clin Proc. 1979; 54(10): 669-74. [PubMed: 39202]

34. Togias A. H1-receptors: localization and role in airway physiology and in immune functions. J Allergy Clin Immunol. 2003; 112(4 Suppl):S60-8. [PubMed: 14530790]

35. Brandes LJ, Lorne J, LaBella FS. Identification of intracellular histamine receptors (HIC) that regulate cell proliferation. Adv Biosciences (Oxford). 1993; 89:31-41. Histamine inrmal and Cancer Cell Prolification.

36. Sroa N, Magro CM. Pediatric primary cutaneous marginal zone lymphoma: in association with chronic antihistamine use. J Cutan Pathol. 2006; 33 (Suppl 2):1-5. [PubMed: 16972944]

37. Brandes LJ, Davie JR, Paraskevas F, Sukhu B, Bogdanovic RP, LaBella FS. The antiproliferative potency of histamine antagonists correlates with inhibition of binding of [3H]-histamine to novel intracellular receptors (HIC) in microsomal and nuclear fractions of rat liver. Agents Actions Suppl. 1991; 33:325-42. [PubMed: 2053513]

38. Clarke CA, Undurraga DM, Harasty PJ, Glaser SL, Morton LM, Holly EA. Changes in cancer registry coding for lymphoma subtypes: reliability over time and relevance for surveillance and study. Cancer Epidemiol Biomarkers Prev. 2006; 15(4):630-8. [PubMed: 16614102]

39. Morton LM, Wang SS, Cozen W, Linet MS, Chatterjee N, Davis S, et al. Etiologic heterogeneity among non-Hodgkin lymphoma subtypes. Blood. 2008; 112(13):5150-60. [PubMed: 18796628] 


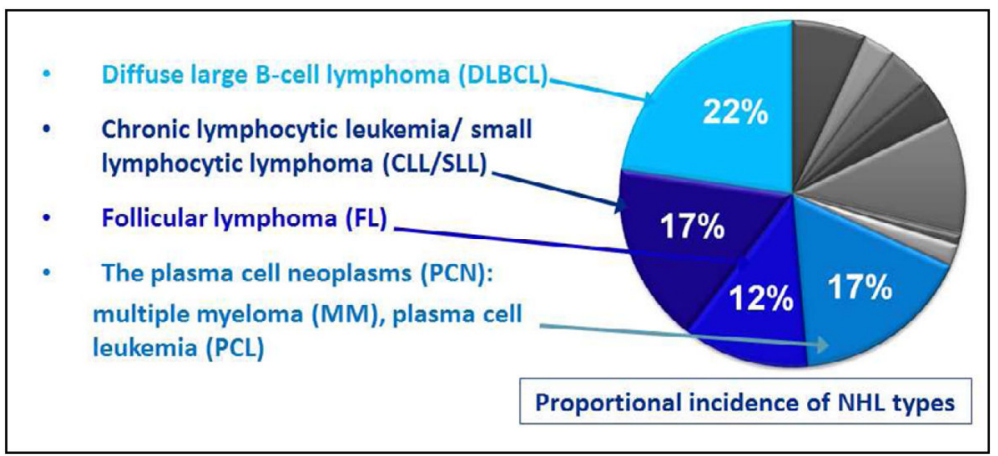

Figure 1. Proportional incidence of NHL subtypes

Proportional incidence data from Morton et al 2008; based on 17 SEER registries, 20012003. ${ }^{39}$ 
Table 1

Classification of TCA use.

\begin{tabular}{|c|c|}
\hline Exposure Group & Definition \\
\hline Type & Amitriptyline, Doxepin, Imipramine, Nortriptyline; ${ }^{a}$ Other $b$ \\
\hline \multirow[t]{2}{*}{ Number of prescriptions } & Ever-use ( $\geq 2$ prescriptions) \\
\hline & Long-term use ( $\geq 10$ prescriptions) \\
\hline Average & Low: $<50 \mathrm{mg} /$ day \\
\hline Dose & High: $\geq 50 \mathrm{mg} /$ day $\left(\right.$ or equivalent) ${ }^{c}$ \\
\hline Cumulative & Low: $\unlhd 1000$ mg-prescriptions \\
\hline Dose & High: >1000 mg-prescriptions \\
\hline \multirow[t]{3}{*}{ Recency } & Any recent $(<5 \text { yrs since last use })^{d}$ \\
\hline & Any very recent $(<2 \text { yrs since last use })^{d}$ \\
\hline & Only non-recent ( $\geq 5$ yrs since last use $)^{d}$ \\
\hline \multicolumn{2}{|c|}{ Includes subjects who filled $\geq 2$ prescriptions for that type } \\
\hline \multicolumn{2}{|c|}{ 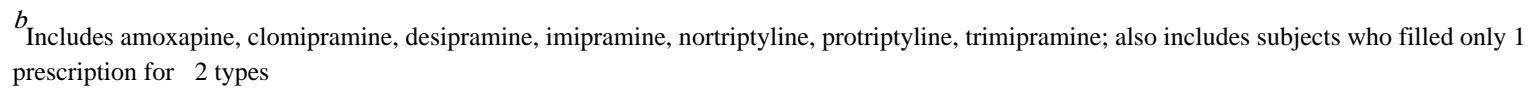 } \\
\hline
\end{tabular}


Table 2

Characteristics of NHL cases diagnosed between 1980 and 2011, and matched controls, all members of Group Health.

\begin{tabular}{|c|c|c|}
\hline & Cases n (\%) & Controls n (\%) \\
\hline TOTAL & $2,768(100)$ & $22,127(100)$ \\
\hline \multicolumn{3}{|l|}{ Age at reference date } \\
\hline$<55$ years & $523(19)$ & $4,215(19)$ \\
\hline $55-64$ years & $594(21)$ & $4,736(21)$ \\
\hline $65-74$ years & $729(26)$ & $5,857(26)$ \\
\hline $75+$ years & $922(33)$ & $7,319(33)$ \\
\hline \multicolumn{3}{|l|}{ Sex } \\
\hline Male & $1,551(56)$ & $12,400(56)$ \\
\hline Female & $1,217(44)$ & $9,727(44)$ \\
\hline \multicolumn{3}{|l|}{ Year diagnosed } \\
\hline $1980-1990$ & $536(19)$ & $4,280(19)$ \\
\hline $1991-2000$ & $958(35)$ & $7,658(35)$ \\
\hline 2001-2011 & $1,274(46)$ & $10,189(46)$ \\
\hline \multicolumn{3}{|c|}{ Length of time for which pharmacy data were available prior to the reference date } \\
\hline $2-5 \mathrm{yrs}$ & $635(23)$ & $5,089(23)$ \\
\hline $6-10 \mathrm{yrs}$ & $617(22)$ & $4,868(22)$ \\
\hline $11-20 \mathrm{yrs}$ & $893(32)$ & $7,081(32)$ \\
\hline $21+\mathrm{yrs}$ & $623(23)$ & $5,089(23)$ \\
\hline \multicolumn{3}{|l|}{ Race $b$} \\
\hline Asian & $82(3)$ & $585(4)$ \\
\hline American Indian/Alaska Native & $21(1)$ & $191(1)$ \\
\hline Black/African American & $89(3)$ & $422(3)$ \\
\hline Native Hawaiian/Pacific Islander & $6(0)$ & $77(1)$ \\
\hline White & $2,541(93)$ & $13,167(91)$ \\
\hline
\end{tabular}

'Period of time over which exposure (TCA use) could be ascertained, i.e. the period before the reference date and after the start of the subject's enrollment at Group Health or the start of the pharmacy database (1977), whichever was later.

${ }^{b}$ Missing for $1 \%$ of cases, $35 \%$ of controls. $>99 \%$ of matched sets had race information on the case and $\geq 1$ control. 


\section{Table 3a}

Risk of NHL and common subtypes associated with TCA use, including ever-use, number of prescriptions, dose, type, recency.

\begin{tabular}{|c|c|c|c|}
\hline & $\begin{array}{l}\text { Cases }(\mathrm{n}=\mathbf{2 , 7 6 8}) \\
\quad \mathrm{n}(\%)\end{array}$ & $\begin{array}{l}\text { Controls }(\mathrm{n}=\mathbf{2 2 , 1 2 7}) \\
\mathrm{n}(\%)\end{array}$ & $\begin{array}{l}\text { Any NHL } \\
\text { OR }(95 \% \text { CI }) f\end{array}$ \\
\hline Non-user (0 prescriptions) & $2,176(79)$ & $18,107(82)$ & 1.0 \\
\hline Ever-use ( $\geq 2$ prescriptions) & $420(15)$ & $2,837(13)$ & $1.1(1.0-1.3)$ \\
\hline \multicolumn{4}{|l|}{ Number of Prescriptions } \\
\hline Short-term use (2-9) & $234(8)$ & $1,729(8)$ & $1.0(0.9-1.2)$ \\
\hline Long-term use $(\geq 10)$ & $186(7)$ & $1,108(5)$ & $1.2(1.0-1.5)$ \\
\hline$(220)$ & $118(4)$ & $651(3)$ & $1.3(1.0-1.7)$ \\
\hline$(\geq 30)$ & $83(3)$ & $457(2)$ & $1.3(1.0-1.7)$ \\
\hline \multicolumn{4}{|l|}{ Average Dose $^{a}$} \\
\hline Low ( $\$ 50 \mathrm{mg} /$ day) & $377(14)$ & $2,587(12)$ & $1.1(1.0-1.3)$ \\
\hline High (>50 mg/day) & $31(1)$ & $183(1)$ & $1.2(0.7-1.8)$ \\
\hline \multicolumn{4}{|l|}{ Cumulative Dose $b$} \\
\hline Low ( $\unlhd, 000$ mg-prescriptions) & $336(12)$ & $2,350(11)$ & $1.1(0.9-1.3)$ \\
\hline High (>1,000 mg-prescriptions) & $72(3)$ & $420(2)$ & $1.2(0.9-1.6)$ \\
\hline \multicolumn{4}{|l|}{ TCA Type ( 22 prescriptions) } \\
\hline Amitriptyline & $173(6)$ & $1,091(5)$ & $1.2(1.0-1.4)$ \\
\hline Doxepin & $132(5)$ & $1,003(5)$ & $1.0(0.8-1.3)$ \\
\hline Imipramine & $68(2)$ & $471(2)$ & $1.0(0.8-1.4)$ \\
\hline Nortriptyline & $115(4)$ & $720(3)$ & $1.1(0.9-1.4)$ \\
\hline \multicolumn{4}{|l|}{ Recency } \\
\hline Non-recent use (only) ${ }^{c}$ & $132(5)$ & $1,007(5)$ & $0.9(0.6-1.5)$ \\
\hline Recent use (any) ${ }^{d}$ & $288(10)$ & $1,830(8)$ & $1.2(0.9-1.7)$ \\
\hline Very recent use (any) ${ }^{e}$ & $206(7)$ & $1,176(5)$ & $1.3(1.1-1.6)$ \\
\hline \multicolumn{4}{|l|}{$a_{\text {standardized by type }}$} \\
\hline \multicolumn{4}{|c|}{$\begin{array}{l}b \\
\text { standardized by type; calculated as average dose times number of prescriptions; range: } 10 \text { to } 21,109 \text { mg-prescriptions (90\% are }<1220 \mathrm{~m} \\
\text { prescriptions) }\end{array}$} \\
\hline \multicolumn{4}{|c|}{$c^{c}$ all use on record occurred $\geq 5$ y before reference date } \\
\hline \multicolumn{4}{|c|}{$d$ any use on record occurred $<5$ y before reference date } \\
\hline \multicolumn{4}{|c|}{$e_{\text {any }}$ use on record occurred $<2$ y before reference date } \\
\hline
\end{tabular}




\section{Table 3b}

Risk of NHL and common subtypes associated with TCA use, including ever-use, number of prescriptions, dose, type, recency.

\begin{tabular}{|c|c|c|c|c|}
\hline & DLBCL & CLL/SLL & FL & PCN \\
\hline & OR $(95 \% \mathrm{CI}) f$ & OR $(95 \% \mathrm{CI}) f$ & OR $(95 \%$ CI $) f$ & OR $(95 \%$ CI $) f$ \\
\hline Non-user (0 prescriptions) & 1.0 & 1.0 & 1.0 & 1.0 \\
\hline Ever-use ( $\geq 2$ prescriptions) & $1.1(1.0-1.2)$ & $1.2(1.0-1.5)$ & $0.9(0.6-1.3)$ & $1.0(0.8-1.3)$ \\
\hline \multicolumn{5}{|l|}{ Number of Prescriptions } \\
\hline Short-term use (2-9) & $1.1(0.9-1.2)$ & $1.0(0.7-1.3)$ & $1.1(0.7-1.6)$ & $0.9(0.6-1.2)$ \\
\hline Long-term use $(\geq 10)$ & $1.2(1.0-1.4)$ & $1.5(1.1-2.0)$ & $0.7(0.4-1.2)$ & $1.2(0.8-1.7)$ \\
\hline$(\geq 20)$ & $1.2(1.0-1.5)$ & $1.8(1.2-2.5)$ & $0.6(0.3-1.2)$ & $1.3(0.8-2.1)$ \\
\hline$(230)$ & $1.2(1.0-1.5)$ & $1.8(1.2-2.7)$ & $0.8(0.4-1.7)$ & $1.3(0.7-2.2)$ \\
\hline \multicolumn{5}{|l|}{ Average Dose ${ }^{a}$} \\
\hline Low ( $\$ 50 \mathrm{mg} /$ day) & $1.1(1.0-1.2)$ & $1.2(1.0-1.5)$ & $1.0(0.7-1.4)$ & $1.0(0.8-1.3)$ \\
\hline High $(>50 \mathrm{mg} /$ day $)$ & $1.1(0.8-1.5)$ & $1.2(0.7-2.2)$ & $0.9(0.4-2.2)$ & $1.0(0.5-2.0)$ \\
\hline \multicolumn{5}{|l|}{ Cumulative Dose $b$} \\
\hline Low ( $₫ 000$ mg-rxs) & $1.1(0.9-1.4)$ & $1.1(1.0-1.2)$ & $1.1(0.8-1.5)$ & $1.0(0.8-1.3)$ \\
\hline High (>1000 mg-rxs) & $1.1(0.8-1.4)$ & $1.6(1.0-2.5)$ & $0.5(0.2-1.3)$ & $1.0(0.5-1.8)$ \\
\hline \multicolumn{5}{|l|}{ TCA Type ( $\geq 2$ prescr.) } \\
\hline Amitriptyline & $1.2(1.0-1.4)$ & $1.5(1.1-2.0)$ & $0.9(0.5-1.4)$ & $1.1(0.7-1.6)$ \\
\hline Doxepin & $1.0(0.8-1.2)$ & $1.1(0.8-1.6)$ & $0.9(0.5-1.7)$ & $0.9(0.6-1.4)$ \\
\hline Imipramine & $1.1(0.8-1.3)$ & $1.2(0.8-1.9)$ & $0.5(0.2-1.2)$ & $0.8(0.4-1.5)$ \\
\hline Nortriptyline & $1.2(1.0-1.5)$ & $1.5(1.0-2.2)$ & $0.8(0.4-1.7)$ & $1.0(0.6-1.7)$ \\
\hline \multicolumn{5}{|l|}{ Recency } \\
\hline Non-recent use (only) ${ }^{c}$ & $1.0(0.9-1.2)$ & $1.3(1.0-1.7)$ & $1.1(0.7-1.9)$ & $1.0(0.7-1.5)$ \\
\hline Recent use (any) ${ }^{d}$ & $1.1(1.0-1.3)$ & $1.0(0.7-1.4)$ & $0.8(0.5-1.2)$ & $1.0(0.7-1.4)$ \\
\hline Very recent use (any) ${ }^{e}$ & $1.5(1.0-2.2)$ & $1.7(1.2-2.5)$ & $1.2(0.8-1.9)$ & $1.2(0.8-1.9)$ \\
\hline \multicolumn{5}{|l|}{$a_{\text {standardized by type }}$} \\
\hline \multicolumn{5}{|c|}{$\begin{array}{l}b \\
\text { standardized by type; calculated as average dose times number of prescriptions; range: } 10 \text { to } 21,109 \text { mg-prescriptions (90\% are }<1220 \mathrm{~m} \\
\text { prescriptions) }\end{array}$} \\
\hline \multicolumn{5}{|c|}{$c_{\text {all use on record occurred } \geq 5 \text { y before reference date }}$} \\
\hline \multicolumn{5}{|c|}{$d$ any use on record occurred $<5$ y before reference date } \\
\hline \multicolumn{5}{|c|}{$e_{\text {any use on record occurred }<2 \text { y before reference date }}$} \\
\hline
\end{tabular}


Table 4

Risk of NHL associated with TCA use, including ever-use, number of prescriptions, dose, type, recency, for persons with $\geq 5$ years and $\geq 10$ years of pharmacy data.

\begin{tabular}{|c|c|c|}
\hline & $\begin{array}{c} \pm \text { years of pharmacy data } \\
\text { OR }(95 \% \text { CI }) f \\
\end{array}$ & $\begin{array}{c}\geq 10 \text { years of pharmacy data } \\
\text { OR }(95 \% \text { CI } f\end{array}$ \\
\hline Non-user (0 prescriptions) & $1.0(\mathrm{ref})$ & 1.0 (ref) \\
\hline Ever-use ( $\geq 2$ prescriptions) & $1.2(1.0-1.3)$ & $1.0(0.8-1.2)$ \\
\hline \multicolumn{3}{|l|}{ Number of Prescriptions } \\
\hline Short-term use (2-9) & $1.1(0.9-1.3)$ & $1.0(0.8-1.3)$ \\
\hline Long-term use $(\geq 10)$ & $1.2(1.0-1.5)$ & $1.0(0.8-1.4)$ \\
\hline$(220)$ & $1.3(1.0-1.7)$ & $1.1(0.8-1.6)$ \\
\hline$(\geq 30)$ & $1.3(1.0-1.8)$ & $1.0(0.7-1.5)$ \\
\hline \multicolumn{3}{|l|}{ Average Dose ${ }^{a}$} \\
\hline Low ( $\$ 50 \mathrm{mg} /$ day) & $1.1(1.0-1.3)$ & $1.0(0.9-1.3)$ \\
\hline High (>50 mg/day) & $1.2(0.8-1.8)$ & $1.2(0.6-2.2)$ \\
\hline \multicolumn{3}{|l|}{ Cumulative Dose $a, b$} \\
\hline Low ( $₫ 000$ mg-prescriptions) & $1.1(1.0-1.3)$ & $1.1(0.9-1.3)$ \\
\hline High (>1000 mg-prescriptions) & $1.3(0.9-1.7)$ & $1.0(0.7-1.5)$ \\
\hline \multicolumn{3}{|l|}{ Recency } \\
\hline Non-recent use (only) ${ }^{c}$ & $1.0(0.6-1.5)$ & $0.8(0.4-1.3)$ \\
\hline Recent use (any) ${ }^{d}$ & $1.3(0.9-1.9)$ & $1.1(0.7-1.9)$ \\
\hline Very recent use (any) ${ }^{e}$ & $1.3(1.1-1.7)$ & $1.2(0.9-1.7)$ \\
\hline \multicolumn{3}{|l|}{ TCA Type ( $\geq 2$ prescriptions) } \\
\hline Amitriptyline & $1.3(1.0-1.6)$ & $1.1(0.8-1.5)$ \\
\hline Doxepin & $1.0(0.8-1.3)$ & $0.8(0.5-1.1)$ \\
\hline Imipramine & $1.0(0.7-1.4)$ & $0.8(0.5-1.3)$ \\
\hline Nortriptyline & $1.2(0.9-1.6)$ & $1.4(1.0-1.9)$ \\
\hline \multicolumn{3}{|l|}{$a_{\text {standardized by type }}$} \\
\hline \multicolumn{3}{|c|}{$b_{\text {range: }} 10$ to $21,109 \mathrm{mg}$-days ( $90 \%$ are $<1220 \mathrm{mg}$-days) } \\
\hline \multicolumn{3}{|c|}{$c$ all use on record occurred $\geq 5$ y before reference date } \\
\hline \multicolumn{3}{|c|}{$d$ any use on record occurred $<5$ y before reference date } \\
\hline \multicolumn{3}{|c|}{$e_{\text {any }}$ use on record occurred $<2$ y before reference date } \\
\hline
\end{tabular}


Table 5

Risk of NHL associated with SSRI use, including ever-use, duration (number of prescriptions), recency (adjusted for opioid use and race)

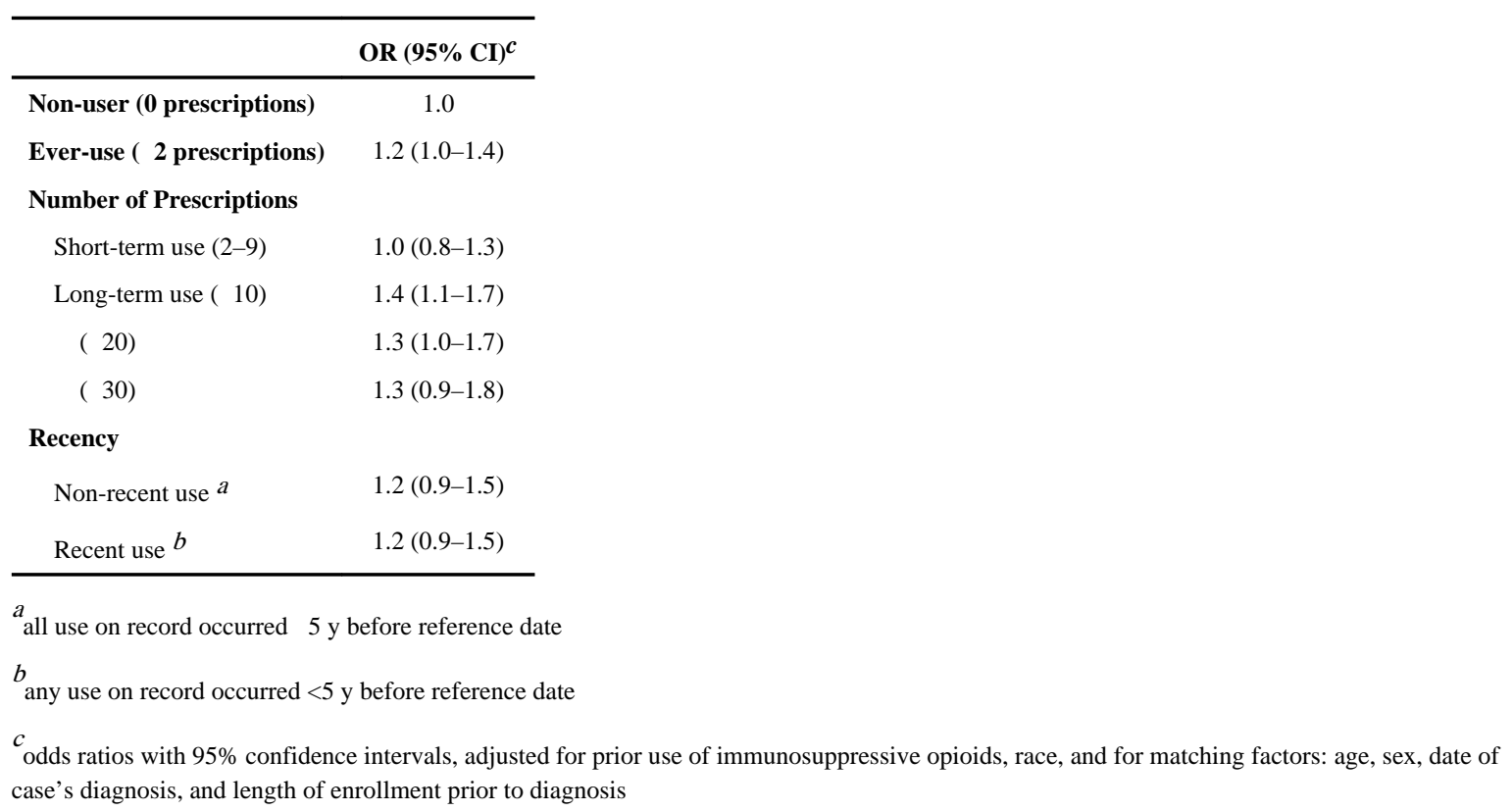

